\title{
Preoperative and intraoperative localisation of gastrointestinal bleeding of obscure origin
}

\author{
W Y LAU, S T FAN, S H WONG, K P WONG, G P POON, K W CHU, \\ W C YIP, AND K K WONG \\ From the Government Surgical Unit, Queen Mary Hospital, Pokfulam Road, Hong Kong
}

SUMMARY In the past six years, 37 patients with gastrointestinal bleeding of obscure origin had their bleeding sites localised preoperatively or intraoperatively. Preoperative investigations followed a regime consisting of endoscopy, barium meal and follow through, small bowel enema, ${ }^{9 \% \mathrm{~m}} \mathrm{Tc}$ pertechnetate scan, ${ }^{99 \mathrm{~m}} \mathrm{Tc}$-labelled red blood cell scan and selective coeliac and mesenteric angiography. Bleeding lesions were localised preoperatively in 36 patients. In one patient, diagnostic laparotomy had to be carried out immediately before any investigation because the bleeding was severe. At operation, angiosarcoma of ileum was found. Unless preoperative investigations showed the lesions to be in anatomically fixed organs like the duodenum or colon, the lesions had still to be found at operation. Palpation and transillumination detected the lesion intraoperatively in 21 patients while only some lesions were found in three patients with multiple lesions. Sigmoidoscopy through enterotomies was required in one patient. Intraoperative enteroscopy was done for small lesions not found grossly at operation in nine patients, to detect additional lesions in three patients or to rule out suspicious lesion shown on preoperative tests in one patient. In another patient with diffuse lymphoma of small bowel with bleeding from only a small segment of jejunum, injection of methylene blue intraoperatively through a previously placed angiographic catheter stained the bleeding segment of jejunum blue. This segment was identified easily and resected. These preoperative and intraoperative localisation procedures were simple and effective and we recommend them to be used more freely.

Gastrointestinal bleeding is a common emergency, accounting for about 500 to 1200 admissions per million population per year..$^{-4}$ Fortunately most of these bleeding lesions are situated at sites easily accessible to endoscopic examination and diagnosis can speedily be made in 80 to $90 \%$ of patients by emergency oesophagogastroduodenoscopy alone. $-\infty$ In the minority that remains undiagnosed after conventional investigations, many will never bleed again." A problem, however, arises when bleeding becomes massive, continuous or recurrent, and when the bleeding lesions are malignant. The investigation of such patients is notoriously difficult and very often a disproportionately large amount of

Address for correspondence: Dr W Y Lau, Government Surgical Unit, Queen Mary Hospital, Pokfulam Road, Hong Kong.

Received for publication 7 November, 1986. medical resources and time are used. ${ }^{10}$ Localisation of the bleeding source is important in the management because once it is found, diagnosis becomes simple and a rational and hopefully curative treatment can be offered. Localisation can be done preoperatively or intraoperatively with a wide range of investigatory procedures, the correct choice of which can sometimes be difficult. Our experience in the management of such patients in the past six years form the basis of this report.

\section{Methods}

PATIENTS

Between 1979 and 1985, 2751 patients with gastrointestinal bleeding were admitted into our unit. Thirty four patients $(1 \cdot 2 \%)$ presented with bleeding of obscure origin which is defined as a failure to find 
the source of bleeding after conventional investigations. These include at least one, and often more, emergency upper gastrointestinal endoscopy, barium meal, sigmoidoscopy, barium enema and colonoscopy. During this period, there were two patients with Peutz-Jeghers syndrome and one with blue rubber bleb naevus syndrome." The facial stigmata provided the spot diagnosis. The bleeding lesions could occur from any part of the gastrointestinal tract, however, and the problem of locating these lesions was the same as that in other cases of bleeding of obscure origin and thus they were included in this review.

The average age of our patients was 54 years (range 2-82 years) and the median time from the first bleeding to diagnosis was 1.9 years (range 1 month to 8 years). All of them had recurrent or massive bleeding. There were 24 men and 13 women.

A careful history, including a good family history of gastrointestinal bleeding, was routinely taken. Blood dyscrasias, clotting defects and other metabolic disorders were excluded by laboratory investigations. When conventional investigations as defined above failed to reveal the bleeding source, the patients were investigated as follows.

PREOPERATIVE LOCALISATION

${ }^{{ }^{9 m} \mathrm{~m}}$ Tc pertechnetate scan for Meckel's diverticulum was done on young patients. If the scan was negative, or for elderly patients, barium meal and follow through was done. This was replaced by small bowel enema in the last year of the study. When this contrast examination was negative, or there was active bleeding, selective coeliac and mesenteric angiography was carried out. As angiography could not be done for at least one week after barium examination because details would be obscure by the barium in the bowel, emergency angiography should be done before any barium examination when the bleeding was active. Angiography was followed by ${ }^{94 \mathrm{~m}}$ Tc-labelled red blood cell scan when it failed to reveal the bleeding sites. For 36 patients, the bleeding lesions were localised preoperatively and laparotomy was carried out for treatment. Diagnostic laparotomy, however, was required immediately in one patient with very active bleeding before any investigation. At operation, a large, bleeding angiosarcoma of the ileum was found.

It is important to realise that diagnosis and localisation of the bleeding lesions are not the same. Sometimes the pathological nature of the bleeding lesions are known but the bleeding sites have to be localised as in Peutz-Jeghers and blue rubber bleb naevus syndromes; or the bleeding sites have been localised by emergency angiography but the pathological nature of the lesions remains unknown.
Unless preoperative investigation showed the lesions to lie in anatomically fixed organs, small lesions had still to be found intraoperatively.

INTRAOPERATIVE LOCALISATION

Methods include (1) palpation, (2) transillumination, (3) enterotomies and eversion of the mucosa, (4) sigmoidoscopy through enterotomies, (5) colonoscopy through mouth, "1 anus, " or enterotomy and (6) injection of methylene blue through previously placed angiographic catheters. '?

When palpation and transillumination failed to localise the lesions, the other special intraoperative procedures mentioned were used. These procedures could also be used in (1) multiple small bleeding lesions in the small intestine when it was difficult to localise all lesions by palpation and transillumination, (2) extensive tumour involvement of the intestine with bleeding only from a short segment of intestine, (3) massive bleeding requiring emergency surgery before preoperative localisation was possible and (4) diagnostic laparotomy when preoperative localisation failed to find the lesion.

\section{Results}

PREOPERATIVE LOCAIISATION (Table 1)

${ }^{*} \mathrm{~m}$ Tc pertechnetate scan was carried out on 10 patients below the age of 30 . Five out of six patients who were later confirmed to have Meckel's diverticuli had a positive scan, giving a false negative rate of $17 \%$.

Barium meal and follow through was done on 21 patients and small bowel enema on six. Eight out of the 27 examinations revealed either tumours or ulcers in the small intestine. In a patient who had Polya gastrectomy 10 years ago, gastroscopy and selective angiography revealed bleeding from the afferent loop. Barium meal and follow through, however, failed to show the afferent loop. A catheter was introduced into the afferent loop through a gastroscope and injection of barium revealed a lesion at the end of it. Laparotomy showed it to be a leiomyosarcoma (Fig. 1). These barium examinations, however, had their limitations. Only larger polyps in the two patients with Peutz-Jeghers syndrome were shown up. Most of the smaller polyps had to be found at operation by intraoperative enteroscopy. In a patient with aortoduodenal fistula with a thrombus in the duodenum, barium meal and follow through misdiagnosed it to be a duodenal tumour (Fig. 2). In the last year of our study, six patients had small bowel enema; although small bowel enemas were technically more difficult to perform than barium meal and follow through, they gave much better delineation of small bowel lesions. 
Table 1 Usefulness of preoperative diagnostic tests in bleeding of obscure origin*

\begin{tabular}{|c|c|c|c|c|c|}
\hline Pathology & Patients (n) & Meckel's scan & $\begin{array}{l}\text { Ba Meal FT/small } \\
\text { bowel enema }\end{array}$ & $\begin{array}{l}\text { Selective } \\
\text { angiography }\end{array}$ & $\begin{array}{l}R B C \\
\text { scan }\end{array}$ \\
\hline \multicolumn{6}{|l|}{ Tumours } \\
\hline Smooth muscle tumours of gut & 6 & - & $4 / 4$ & $2 / 2$ & - \\
\hline Lymphoma of gut & 4 & - & $2 / 3$ & $2 / 2$ & $1 / 1$ \\
\hline Angiosarcoma of ilcum & 1 & - & - & - & - \\
\hline Afferent loop leiomyosarcoma & 1 & - & $0 / 1$ & - & - \\
\hline Carcinoma of jejunum & 1 & - & $1 / 1$ & - & - \\
\hline \multicolumn{6}{|l|}{ Arteriovenous malformation } \\
\hline A V M small bowel & 3 & $0 / 1$ & $0 / 2$ & $3 / 3$ & $0 / 1$ \\
\hline A V M rectum & 1 & $0 / 1$ & $0 / 1$ & $1 / 1$ & - \\
\hline Angiodysplasia of caecum & 4 & - & $0 / 2$ & $4 / 4$ & - \\
\hline \multicolumn{6}{|l|}{ Others } \\
\hline Meckel's diverticuli & 7 & $5 / 6$ & $0 / 4$ & $1 / 2$ & $2 / 2$ \\
\hline Jejunal diverticuli & 1 & - & $0 / 1$ & $1 / 1$ & - \\
\hline Tuberculous ileal ulcers & 1 & $0 / 1$ & $0 / 1$ & $1 / 1$ & - \\
\hline Non-specific ileal ulcers & 2 & $0 / 1$ & $1 / 2$ & $1 / 2$ & $1 / 1$ \\
\hline Leaking aortoduodenal fistula & 1 & - & $0 / 1$ & - & - \\
\hline Ischaemic colitis & 1 & - & $0 / 1$ & $1 / 1$ & $1 / 1$ \\
\hline \multicolumn{6}{|l|}{ Hereditary } \\
\hline Peutz-Jeghers syndrome & 2 & - & $2 / 2 \dagger$ & $2 / 2$ & - \\
\hline Blue rubber bleb naevus syndrome & 1 & - & $1 / 1 \dagger$ & $1 / 1$ & - \\
\hline Total & 37 & $5 / 10$ & $11 / 27$ & $20 / 22$ & $5 / 6$ \\
\hline
\end{tabular}

*Usefulness $=$ number of diagnostic tests/number of tests carried out; †only some lesions detected.
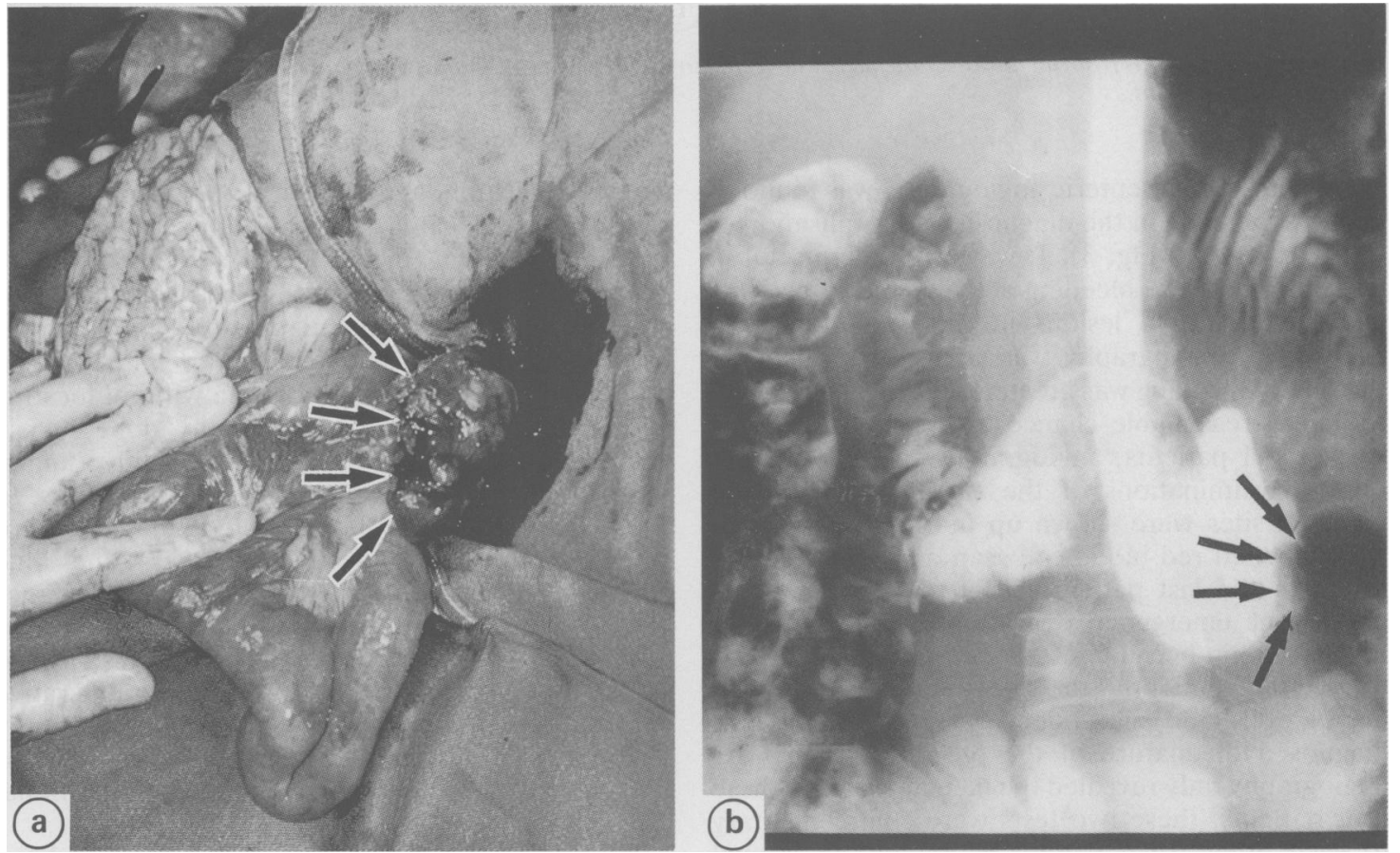

Fig. 1 (a) Leiomyosarcoma of the afferent loop; (b) tumour shown by injection of barium through a gastroscope. 

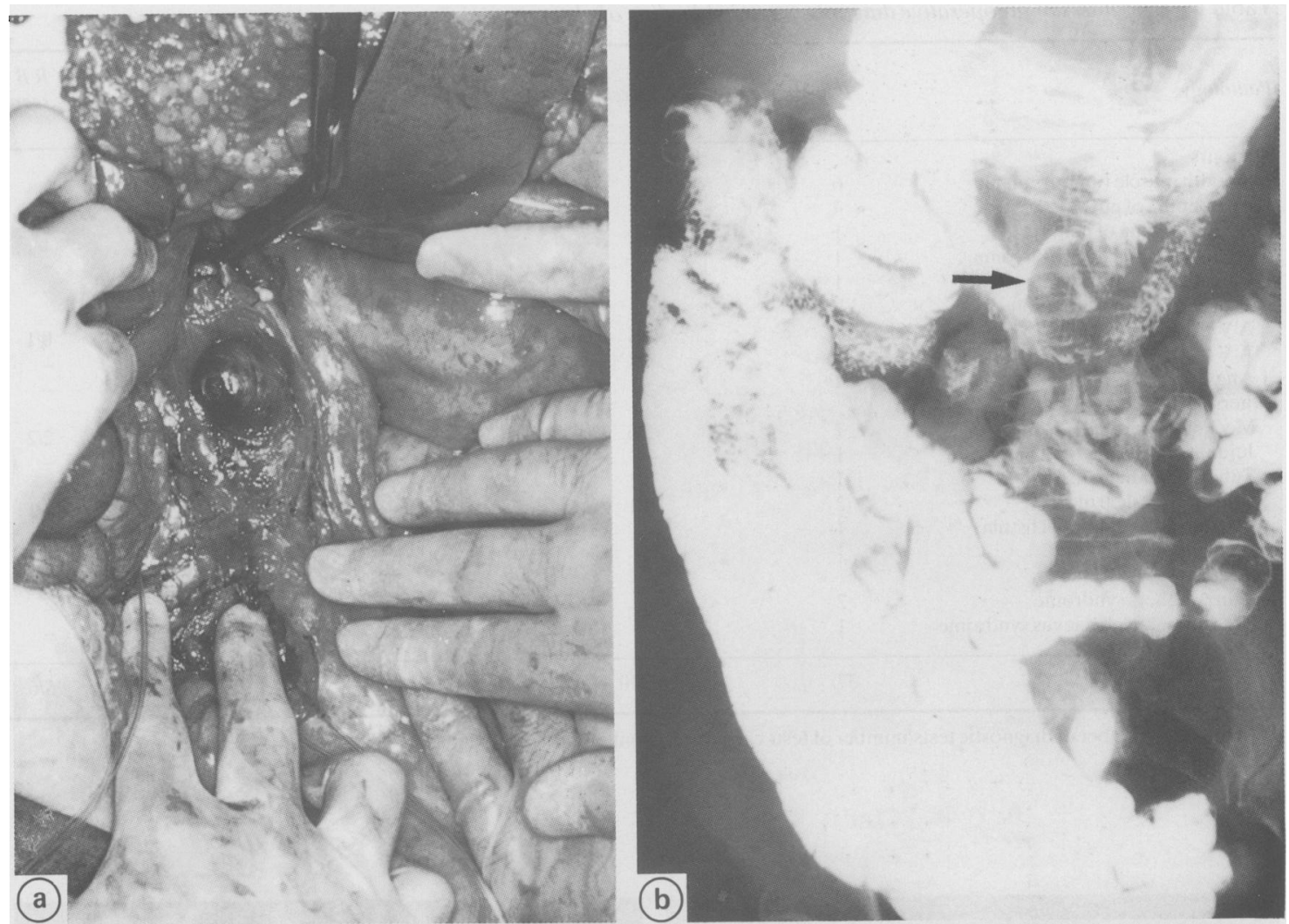

Fig. 2 (a) A thrombus from an aorto-duodenal fistula found in duodenum; (b) barium meal and follow through showed a 'tumour' in duodenum.

Coeliac and mesenteric angiography was found to be most valuable in the diagnosis and localisation of vascular lesions (Fig. 3). It was especially useful in patients who were bleeding actively and in patients who had multiple lesions in the small intestine. Emergency angiography was performed whenever the rate of bleeding was greater than $1 \mathrm{ml}$ per minute to give a reasonable chance to show the bleeding sites. In 11 patients, angiography was done before barium examinations of the small intestine. The bleeding sites were shown up in 10 patients while ${ }^{9{ }^{*} \mathrm{~m}}$ Tc-labelled red blood cell scan demonstrated the lesion in the last patient. Seven of these patients underwent emergency operations without further investigations because of active bleeding. For the other four patients, the bleeding stopped after angiography and subsequent barium examinations diagnosed the nature of the bleeding lesions. As angiography only revealed the bleeding sites in these four patients, these two tests were complementary to each other. In a patient with multiple jejunal diverticuli and another patient with extensive small intestinal lymphoma shown on barium studies, angiography located the bleeding sites at the proximal jejunum (Fig. 4) and these show that both these tests are sometimes necessary. In eight patients who had been investigated previously for chronic and slow gastrointestinal bleeding with barium examinations of the small intestine without locating the lesions, emergency angiography done on six patients during acute bleeding and elective angiography on two patients demonstrated the lesions. In three patients with multiple lesions in the gastrointestinal tract like the Peutz-Jeghers and blue rubber bleb naevus syndromes, only the larger lesions were demonstrated by both barium studies and angiography. The rest of the smaller lesions had to be found intraoperatively by intraoperative localisation. In summary, emergency angiography gave valuable information in 18 of 20 examinations and elective angiography done twice gave additional information to other tests.

${ }^{{ }^{*} \mathrm{~m}} \mathrm{Tc}$-labelled red blood cell scan was carried out on six occasions. Five out of six examinations were 


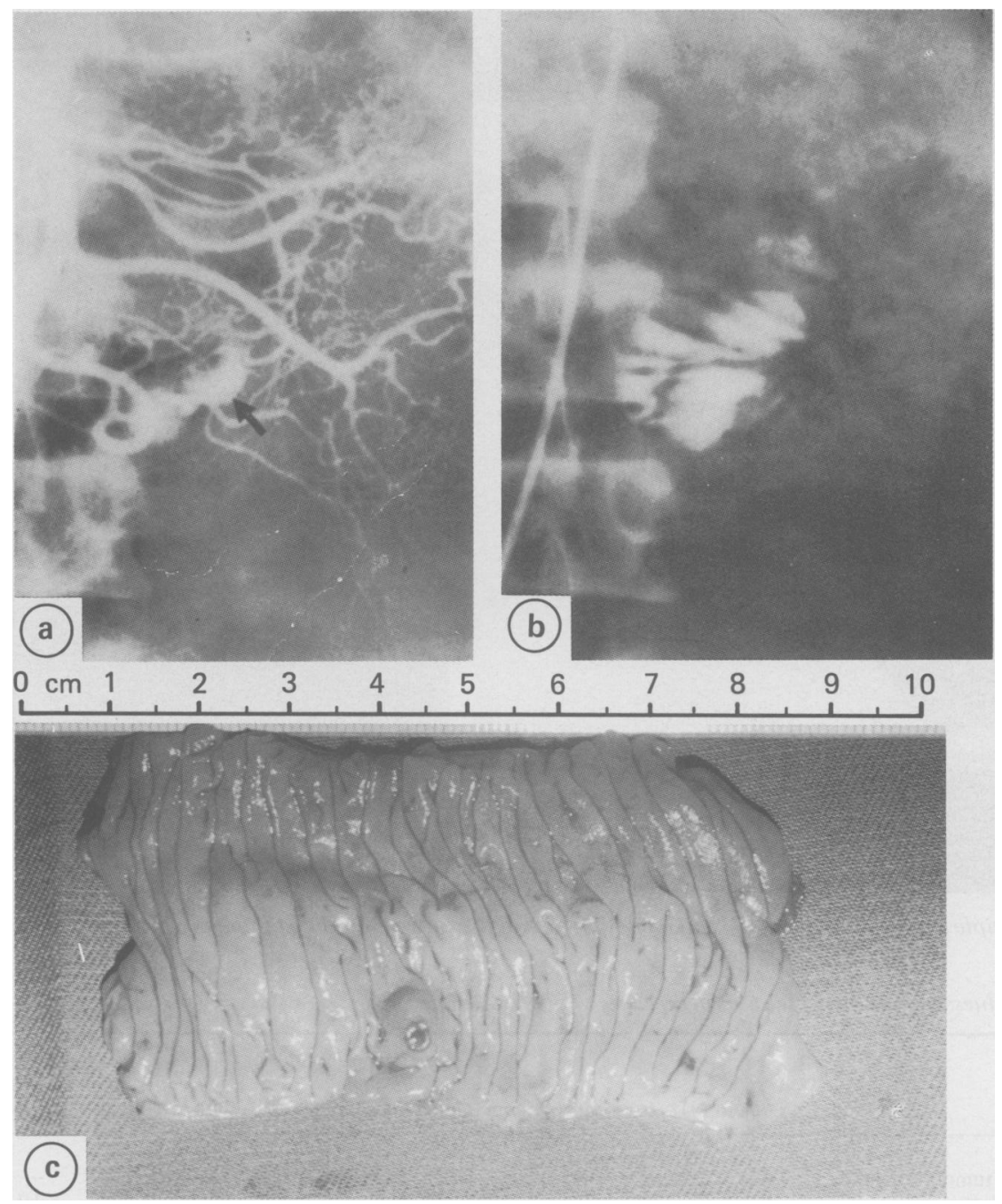

Fig. 3 (a) Superior mesenteric angiography showed actively bleeding lesion in jejunum; (b) contrast in jejunum; (c) the bleeding lesion was an arteriovenous malformation.

positive. On the occasion when it failed, the bleeding had already stopped. This scan could detect a slower rate of bleeding than angiography but it could only give a rough localisation of the bleeding site.

The bleeding lesions were localised preoperatively in 36 patients. We had to do diagnostic laparotomy only once on a patient with such profuse bleeding that emergency operation had to be performed immediately. At operation, a large bleeding angiosarcoma of the ileum was found.

INTRAOPERATIVE LOCALISATION (Table 2)

By simple palpation and transillumination, lesions were detected in 24 of the 37 patients though only part of lesions were palpable in the three patients with Peutz-Jeghers syndrome and blue rubber bleb naevus syndrome.

Multiple enterotomies and eversion of mucosa was messy and troublesome. It was used only once in a patient with blue rubber bleb naevus syndrome. The haemangiomas in the small intestine were so numerous that the whole small intestine could be inspected with this method" after their removal.

Intraoperative enteroscopy was done on 15 patients. This was accomplished by a fibreoptic colonoscope which was inserted through the anus in 14 patients and through an enterotomy (for excision of polyp) and the anus in one patient. The technique 

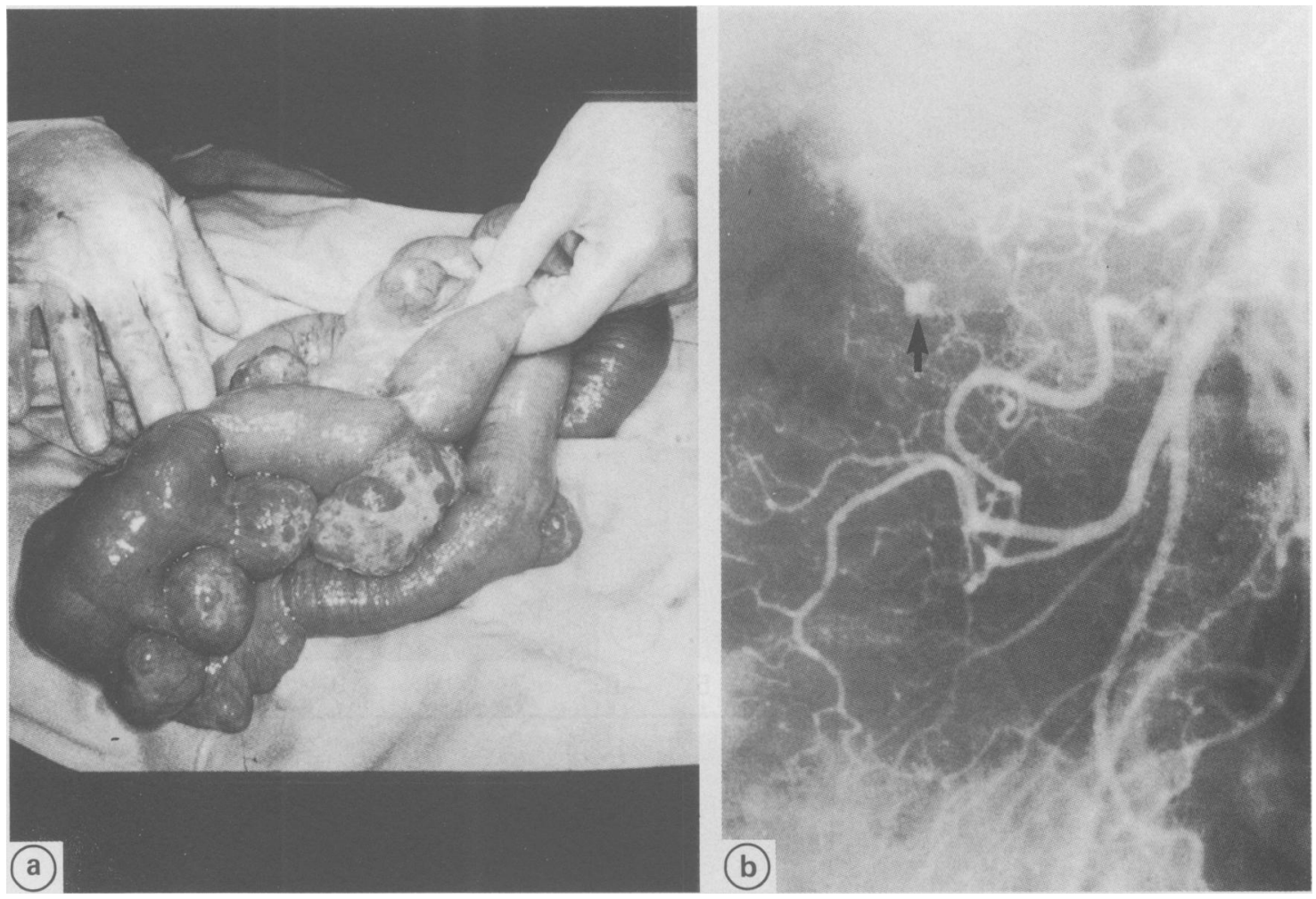

Fig. 4 (a) Multiple jejunal diverticuli; (b) emergency angiography showed bleeding lesion in jejunum.

Table 2 Usefulness of intraoperative tests in bleeding of obscure origin*

\begin{tabular}{|c|c|c|c|c|c|}
\hline Pathology & Patients (n) & $\begin{array}{l}\text { Palpation }+ \\
\text { Transillumination }\end{array}$ & $\begin{array}{l}\text { Sigmoidoscopy } \\
\text { through } \\
\text { enterotomies }\end{array}$ & $\begin{array}{l}\text { Fibreoptic } \\
\text { enteroscopy }\end{array}$ & $\begin{array}{l}\text { Methylene blue } \\
\text { through previously } \\
\text { placed catheter }\end{array}$ \\
\hline \multicolumn{6}{|l|}{ Tumours } \\
\hline Smooth muscle tumours of gut & 6 & $6 / 6$ & - & - & - \\
\hline Lymphoma of gut & 4 & $2 / 4$ & - & $1 / 1$ & $1 / 1$ \\
\hline Angiosarcoma of ileum & 1 & $1 / 1$ & - & - & - \\
\hline Afferent loop leiomyosarcoma & 1 & $1 / 1$ & - & - & - \\
\hline Carcinoma of jejunum & 1 & $1 / 1$ & - & - & - \\
\hline \multicolumn{6}{|l|}{ Arteriovenous malformation } \\
\hline A V M small bowel & 3 & $0 / 3$ & - & $3 / 3$ & - \\
\hline A V M rectum & 1 & $0 / 1$ & - & $1 / 1$ & - \\
\hline Angiodysplasia of caecum & 4 & $0 / 4$ & - & $2 / 4$ & - \\
\hline \multicolumn{6}{|l|}{ Others } \\
\hline Meckel's diverticuli & 7 & $7 / 7$ & - & - & - \\
\hline Jejunal diverticuli & 1 & $1 / 1$ & - & - & - \\
\hline Tuberculous ileal ulcers & 1 & $1 / 1$ & - & - & - \\
\hline Non-specific ileal ulcers & 2 & $0 / 2$ & - & $2 / 2$ & - \\
\hline Leaking aorto-duodenal fistula & 1 & $1 / 1$ & - & - & - \\
\hline Ischaemic colitis & 1 & $0 / 1$ & - & $1 / 1$ & - \\
\hline \multicolumn{6}{|l|}{ Hereditary } \\
\hline Peutz-Jeghers syndrome & 2 & $2 / 2 \dagger$ & - & $2 / 2$ & - \\
\hline Blue rubber bleb naevus syndrome & 1 & $1 / 1 \dagger$ & $1 / 1$ & $1 / 1$ & - \\
\hline Total & 37 & $24 / 37$ & $1 / 1$ & $13 / 15$ & $1 / 1$ \\
\hline
\end{tabular}

${ }^{*}$ Usefulness $=$ number of diagnostic tests/number of tests carried out $;$ tonly some lesions detected. 
has been well described..$^{13}$ This is an easy procedure, the abdominal surgeon helping to manipulate the tip of the fibreoptic enteroscope up the colon through the ileocaecal valve into the terminal ileum. The whole small intestinal mucosa could be inspected by telescoping the small bowel onto the enteroscope. This procedure detected lesions that failed to be detected grossly in nine patients, helped to detect additional lesions in three patients and ruled out suspicious lesion in the jejunum shown on small bowel enema in another patient. In two patients with caecal angiodysplasia, it failed to detect the lesions. Preoperative tests located the bleeding sites to be in the caecum, however, and right hemicolectomy provided cure in both cases.

On only one occasion was injection of methylene blue through a previously placed angiographic catheter required. In this patient who had extensive small bowel lymphoma with bleeding only from a small segment of jejunum, the bleeding site was found by selective angiography preoperatively. The catheter was left in situ. At operation, injection of methylene blue stained the segment of jejunum containing the bleeding ulcers blue. This segment was identified easily and resected.

\section{Discussion}

Investigation of patients with bleeding of obscure origin in the gastrointestinal tract is usually time consuming and difficult. The history given by patients is rarely helpful. A strong family history with facial stigmata might suggest haemorrhagic telangiectasia, Peutz-Jeghers or blue rubber bleb naevus syndrome. Haematemesis is a reliable clue that bleeding is occurring above the duodenojejunal flexure. The colour of the stool is not useful in predicting the site of bleeding as it depends on the transit time of the blood bolus, the amount of blood as well as on the actual site..$^{14}$

Emergency oesophagogastroduodenoscopy should be a routine as acute mucosal lesions can be transient and heal rapidly. ${ }^{1516} \mathrm{~A}$ side view duodenoscopy is useful in diagnosing biliary and pancreatic bleeding. ${ }^{10}$ Urgent colonoscopy also yields valuable information, ${ }^{17}$ though technically it can be difficult when bleeding is profuse. Colonoscopy after a normal double contrast barium enema also give a high diagnostic yield. ${ }^{18}$

The small bowel enema as done by duodenal intubation and infusion of both barium and air or carboxymethyl cellulose solution to obtain double contrast pictures gives superior delineation of small bowel mucosal lesions when compared with a standard barium meal and follow through examination. ${ }^{1920}$ It was useful in the diagnosis of tumours of the small intestine and it should be done when patients present with slow and continuous bleeding in order to diagnose or to rule out neoplastic lesions. It is complementary to angiography when bleeding is more profuse as angiography will most of the time reveal only the bleeding sites while the nature of the lesions has to be demonstrated by barium examinations. The limitation of barium studies is that superficial mucosal lesions and small vascular lesions may not be shown up.

Selective coeliac and mesenteric angiography had proved to be valuable in localising bleeding sites, especially in patients with multiple gastrointestinal lesions, and in diagnosis of arteriovenous malformations and vascular lesions. Similar experience is shared by other authors. ${ }^{102122}$ Emergency angiography should be carried out immediately during active bleeding before barium examinations as barium in the bowel will obscure details of the angiography for at least a week.

${ }^{9} \varphi_{\mathrm{m}} \mathrm{Tc}$ pertechnetate scan is based on the principle that the gamma emitting ion is secreted by the stomach and any ectopic gastric mucosa present in the Meckel's diverticulum in the same manner as chloride, yielding a positive image with the use of a gamma camera. ${ }^{23}$ Such ectopic mucosa is found in 80 to $90 \%$ of patients with symptomatic Meckel's diverticulum..$^{24}$ The false negative rate was 25 to $50 \%{ }^{2526}$ and false positives are seen in a wide range of conditions. ${ }^{10}$ Despite these false negative and false positive rates, a young patient with gastrointestinal bleeding of obscure origin with a positive ${ }^{99 \mathrm{~m}} \mathrm{Tc}$ Pertechnetate scan will strongly support the diagnosis of Meckel's diverticulum.

${ }^{99 m}$ Tc-labelled red blood cell $\operatorname{scan}^{27}$ and ${ }^{99 m} \mathrm{Tc}$ sulphur colloid scan $^{28}$ have the advantage that they can detect slower rate of bleeding than angiography. In animal studies, in the former test, about 30-60 ml of blood must extravasate before it becomes positive while the latter test can detect blood loss of only $0 \cdot 1$ $\mathrm{ml} / \mathrm{min}$. Unfortunately, both techniques have a false negative rate of $40-50 \%$ and false localisation can occur if the isotope lost into the gut moves caudally between scans. ${ }^{10}{ }^{99 m} \mathrm{Tc}$ sulphur colloid scan can be repeated every few hours, if necessary, to monitor rebleeding. In this respect it is superior to the ${ }^{99 \mathrm{~m}} \mathrm{Tc}$ labelled red blood cell scans which could not be repeated in a few days because of the slow decay of the hot spot. ${ }^{27}$ We found ${ }^{99 m}$ Tc-labelled red blood cell scan is more sensitive than angiography in demonstrating bleeding lesions. It gives only a rough localisation of the bleeding sites, however, and no information on the nature of the bleeding lesions. In the era when preoperative investigations to localise the bleeding sites were not available, laparotomy yielded a diagnosis in only about $30 \%$ of cases. ${ }^{2 y}$ The 
search for the bleeding site by direct examination of the gut is usually fruitless even if the patient has bled shortly before operation ${ }^{30}$ and no lesion could be found with post mortem examination in $5-7 \%$ of patients. ${ }^{3132}$ As these patients rarely die of exsanguination when managed conservatively by adequate blood transfusions ${ }^{10}$ we adopted a policy of withholding surgery as far as possible until the source of bleeding is localised. Emergency measures of undertaking a resection (usually a partial gastrectomy or subtotal colectomy) without having identified the bleeding site should nowadays be condemned. ${ }^{1030}$

With a logical plan of approach and advance in technology, fewer and fewer patients will have to struggle on with recurrent anaemia for months or years or will have to take the choice of a diagnostic laparotomy with its poor diagnostic yield. For patients that we fail to localise the bleeding site after complete investigation, we prefer to wait. These patients are closely followed up and immediately reinvestigated when bleeding recurs. For those surgeons who elect to do diagnostic laparotomy, ${ }^{10}$ intraoperative localisation should be used if gross examination fails to find the lesions. We have also found intraoperative enteroscopy most valuable in detecting small lesions, especially when they are multiple and inside the small intestine. Intraoperative enteroscopy is easy, effective and has little complication and should therefore be used more freely. In the rare occasion when intraoperative enteroscopy cannot be used, as in our patient with extensive involvement of the gastrointestinal tract by lymphoma and with active bleeding from only a small segment of small intestine, injection of methylene blue at operation through a previously placed angiographic catheter after selective angiography may be helpful in finding the bleeding lesion.

The authors wish to thank Mrs Sylvia Hulse and Dr Corinna Har for their help in the preparation of this manuscript.

\section{References}

1 Cutler JA, Mendeloff AI. Upper gastrointestinal bleeding: nature and magnitude of the problems in the U.S. Dig Dis Sci 1981; 26: 90s-5s.

2 Johnston SJ, Jones PF, Kyle J, Needham C. Epidemiology and course of gastrointestinal haemorrhage in north-east Scotland. Br Med J 1973; 3: 655-60.

3 Schiller KFR, Truelove SC, Williams DG. Haematemesis and melaena with special reference to factors influencing the outcome. Br Med J 1970; 2: 7-14.

4 Herner B, Kallgard B, Lauritzen G. Haematemesis and Melaena from a limited reception during a 5-year period. Acta Med Scand 1965; 177: 483-92.

5 Hunt PS, Hansky J, Korman MG. Mortality in patients with haematemesis and melaena: a prospective study. Br Med J 1979; 1: 1238-40.

6 Foster DN, Miloszevski KJA, Losowsky MS. Stigmata of recent haemorrhage in diagnosis and prognosis of upper gastrointestinal bleeding. $\mathrm{Br} \operatorname{Med} J$ 1978; 1: 1173-7.

7 Cotton PB, Rosenberg MT, Waldram RPL, Axan ATR. Early endoscopy of oesophagus, stomach and duodenal bulb in patients with haematemesis and melaena. $\mathrm{Br}$ Med J 1983; 2: 505-9.

8 Katon RM, Smith FW. Panendoscopy in the early diagnosis of acute upper gastrointestinal bleeding. Gastroenterology 1973, 65: 728-34.

9 Birke G, Engstedt L. Melaena and haematemesis follow-up investigation with special reference to bleeding of unknown origin. Gastroenterologia 1956; 85: 97-115.

10 Spiller RC, Parkins RA. Recurrent gastrointestinal bleeding of obscure origin: report of 17 cases and a guide to logical management. Br J Surg 1983; 70: 489-93.

11 Wong SH, Lau WY. Blue rubber-bleb naevus syndrome. Dis Colon Rectum 1982; 25: 371-4.

12 Athanasoulis CA, Monrure AC, Greenfield AJ, Ryan JA, Dodson TF. Intraoperative localization of small bowel bleeding sites with combined use of angiographic methods and methylene blue injection. Surgery 1980; 87: 77-84.

13 Lau WY, Fan ST, Chu KW, Yip WC, Poon GP, Wong KK. Intraoperative fibreoptic enteroscopy for bleeding lesion in the small intestine. Br J Surg 1986; 73: 217-8.

14 Hilsman JH. The Colour of blood - containing faeces following the instillation of citrated blood at various level of the small intestine. Gastroenterology 1950; 15: 131-4.

15 Roesch W. Erosions of the upper gastrointestinal tract. Clin Gastroenterol 1978; 7: 623-4.

16 Czaja AJ, McAlhany JC, Andes WA, Pruitt BA. Acute gastric diseases after cutaneous thermal injury. Arch Surg 1975; 110: 600-5.

17 Jensen DM, Machicado GA. Emergency colonoscopy in patients with severe lower gastrointestinal bleeding. Gastroenterology 1980; 80: 1184.

18 Swarbrick ET, Fevre DI, Hunt RH, Thomas BM, Williams CB. Colonoscopy for unexplained rectal bleeding. Br Med J 1978; 2: 1685-7.

19 Ekberg O. Crohn's disease of the small bowel examined by Double contrast technique. Gastrointest Radiol 1977; 1: 355-9.

20 Maglinte DD, Elmore MF, Isenberg M, Dolan PA. Meckel diverticulum - radiologic demonstration by enteroclysis. AJR 1980; 134: 925-32.

21 Crichlow RW, Mosenthal WT, Spiegel PK, House RK. Arteriovenous malformation of the bowel. An obscure cause of bleeding. Am J Surg 1975; 129: 440-8.

22 Sheedy GP, Fulton RE, Atwell DT. Angiographic evaluation of patients with chronic gastrointestinal bleeding. Am J Roentgenol Radium Ther Nucl Med 1975; 123: 338-47.

23 Jewett TC, Duszynski DO, Allen JE. The visualisation of Meckel's diverticulum with Tc pertechnetate. Surgery 1970; 68: 567-70.

24 Rutherford RB, Akers DR. Meckel's diverticulum - A 
review of 148 paediatric patients with special reference to the pattern of bleeding and to meso-diverticular vascular bands. Surgery 1966; 59: 618-28.

25 Rosenthall L, Henry JN, Murphy DA, Freeman LM. Radiopertechnetate imaging of the Meckel's diverticulum. Radiology 1972; 105: 371-3.

26 Duszynski DO, Jewett TC, Allen JF. ${ }^{99 m}$ Tc Na pertechnetate scanning of the abdomen with particular reference to small bowel pathology. Am J Roentgenol Radium Ther Nucl Med 1971; 113: 258-62.

27 McKusick KA, Frelich J, Callahan RJ, Winzelberg GG, Strauss HW. ${ }^{99 m}$ Tc red blood cells for detection of gastrointestinal bleeding. $A J R$ 1981; 137: 1113-8.

28 Alavi A, Ring EJ. Localization of gastrointestinal bleeding, superiority of ${ }^{4 \mathrm{~m}} \mathrm{Tc}$ sulphur colloid compared with angiography. $A J R$ 1981; 137: 741-8.

29 Retzlaft JA, Hazeldorn AB, Bartholomew LG. Abdominal exploration for gastrointestinal bleeding of obscure origin. JAMA 1961; 177: 104-15.

30 Tarin D, Allison DJ, Modlin IM, Neale G. Diagnosis and management of obscure gastrointestinal bleeding. Br Med J 1978; 2: 751-4.

31 Palmer ED. Upper gastrointestinal haemorrhage. Springfield Illinois, Thomas, 1970: 8.

32 Chalmers TC, Zamcheck N, Cortins GW, White FW. Fatal gastrointestinal haemorrhage; clinical pathological correlations in 101 patients. Am J Clin Pathol 1952; 22: 634-5. 